\title{
Geriatric Nutrition Risk Index is an Important Predictor of Cancer-Specific Survival, but not Recurrence-Free Survival, in Patients Undergoing Surgical Resection for Non-Metastatic Renal Cell Carcinoma
}

\author{
Hideaki Miyake Hiromoto Tei Masato Fujisawa \\ Division of Urology, Kobe University Graduate School of Medicine, Kobe, Japan
}

\section{Key Words}

Renal cell carcinoma - Geriatric nutritional risk index •

Surgical resection - Cancer-specific survival .

Recurrence-free survival

\begin{abstract}
Background: The objective of this study was to assess the prognostic value of the Geriatric Nutrition Risk Index (GNRI), a simplified, objective screening parameter of nutrition-related risk for various pathological conditions, on patients with non-metastatic renal cell carcinoma (RCC) who underwent surgical resection. Patients and Methods: This study included 432 consecutive patients with non-metastatic RCC who received complete surgical resection. The prognostic outcomes of these patients were evaluated focusing on the significance of GNRI, calculated from serum albumin and the body mass index. Results: Of the 432 patients, 107 (24.8\%) and $325(75.2 \%)$ were classified into low (GNRI $\leq 98)$ and high (GNRI > 98) nutritional groups, respectively. Both recurrence-free survival and cancer-specific survival in the low nutritional group were significantly poorer compared with those in the high nutritional group. Despite the lack of independent significance as a predictor of recurrence-free sur-
\end{abstract}

\section{KARGER}

두 2016 S. Karger AG, Basel

Fax +41613061234

E-Mail karger@karger.ch

www.karger.com
Accessible online at: www.karger.com/cur vival, GNRI, in addition to microvascular invasion, appeared to be independently associated with cancer-specific survival on multivariate analysis. Conclusion: A low nutritional status evaluated by GNRI may have an unfavorable impact on postoperative cancer control, particularly cancer-specific survival, in non-metastatic RCC patients who received surgical resection.

Copyright $\odot 2016$ S. Karger AG, Basel

\section{Introduction}

Renal cell carcinoma (RCC) accounts for $2-3 \%$ of all adult malignancies and annual estimates of newly diagnosed cases have been steadily increasing over the last decade [1]. RCC is characterized by unique biological features [2], of which the close association with the metabolic status has been shown in both experimental and clinical studies [3-6]. Several genes known to cause RCC share common characteristics involved in metabolism, such as energy, oxygen, iron, and nutrient sensing 
Table 1. Patient characteristics according to the Geriatric Nutrition Risk Index (GNRI)

\begin{tabular}{|c|c|c|c|}
\hline \multirow[t]{2}{*}{ Variables } & \multicolumn{2}{|c|}{ GNRI } & \multirow[t]{2}{*}{$\mathrm{p}$} \\
\hline & $\leq 98(\mathrm{n}=107)$ & $>98(n=325)$ & \\
\hline Age $(\%)$ & & & 0.93 \\
\hline$\leq 70$ years & $41(38.3)$ & $123(37.8)$ & \\
\hline$>70$ years & $66(61.7)$ & $202(62.2)$ & \\
\hline Gender $(\%)$ & & & 0.71 \\
\hline Male & 67 (62.6) & $210(64.6)$ & \\
\hline Female & $40(37.4)$ & $115(35.4)$ & \\
\hline Karnofsky PS (\%) & & & $<0.001$ \\
\hline$<80 \%$ & $40(37.4)$ & $67(20.6)$ & \\
\hline$\geq 80 \%$ & $67(62.6)$ & $258(79.4)$ & \\
\hline Body mass index (\%) & & & $<0.001$ \\
\hline$<22 \mathrm{~kg} / \mathrm{m}^{2}$ & $87(81.3)$ & $103(31.7)$ & \\
\hline$\geq 22 \mathrm{~kg} / \mathrm{m}^{2}$ & $20(18.7)$ & $222(68.3)$ & \\
\hline Neutrophils (\%) & & & 0.15 \\
\hline$>\mathrm{ULN}$ & $96(89.7)$ & $305(93.8)$ & \\
\hline$\leq \mathrm{ULN}$ & $11(10.3)$ & $20(6.2)$ & \\
\hline Hemoglobin (\%) & & & $<0.001$ \\
\hline$<$ LLN & $43(40.2)$ & $248(76.3)$ & \\
\hline$\geq \mathrm{LLN}$ & $64(59.8)$ & $77(23.7)$ & \\
\hline Platelets (\%) & & & $<0.001$ \\
\hline$>$ ULN & $85(79.4)$ & $310(95.4)$ & \\
\hline$\leq \mathrm{ULN}$ & $22(20.6)$ & $15(4.6)$ & \\
\hline Lactate dehydrogenase (\%) & & & 0.72 \\
\hline$>\mathrm{ULN} \times 1.5$ & $99(92.5)$ & $304(93.5)$ & \\
\hline$\leq \mathrm{ULN} \times 1.5$ & $8(7.5)$ & $21(6.5)$ & \\
\hline Albumin $(\%)$ & & & $<0.001$ \\
\hline$<$ LLN & $63(58.9)$ & $12(3.7)$ & \\
\hline$\geq$ LLN & $44(41.1)$ & $313(96.3)$ & \\
\hline Corrected calcium (\%) & & & $<0.001$ \\
\hline$\leq 10 \mathrm{mg} / \mathrm{dL}$ & $59(55.1)$ & $308(94.8)$ & \\
\hline$>10 \mathrm{mg} / \mathrm{dL}$ & $48(44.9)$ & $17(5.2)$ & \\
\hline C-reactive protein (\%) & & & $<0.001$ \\
\hline$\leq \mathrm{ULN}$ & $53(49.5)$ & $251(77.2)$ & \\
\hline$>\mathrm{ULN}$ & $54(50.5)$ & $74(22.8)$ & \\
\hline Pathological T stage (\%) & & & $<0.001$ \\
\hline $\mathrm{T} 1$ & $52(48.6)$ & $233(71.7)$ & \\
\hline $\mathrm{T} 2$ or $\mathrm{T} 3$ & $55(51.4)$ & $92(28.3)$ & \\
\hline Microvascular invasion (\%) & & & $<0.001$ \\
\hline Negative & $65(60.7)$ & $233(71.7)$ & \\
\hline Positive & $42(39.3)$ & $92(28.3)$ & \\
\hline Sarcomatoid component (\%) & & & 0.11 \\
\hline Negative & $101(94.4)$ & $317(97.5)$ & \\
\hline Positive & $6(5.6)$ & $8(2.5)$ & \\
\hline
\end{tabular}

PS = Performance status; ULN = upper limit of normal; LLN $=$ lower limit of normal.

pathways [3], while obesity is a widely accepted risk factor for the development of RCC [4]. Collectively, these findings suggest that RCC has a metabolic association.

Nutritional status has been shown to be an important risk factor associated with the prevalence of postoperative morbidity and mortality in patients with a wide variety of malignant tumors [7-9]. However, it remains controversial whether nutritional status has an impact on the prognosis in patients undergoing surgical treat- ment for RCC [10-15]. For example, Parker et al. [10] reported that despite the association of an increased body mass index (BMI) with a less aggressive disease profile. BMI offers little additional prognostic information over conventional prognostic parameters, while Schips et al. [12] revealed that RCC patients with BMI $>25 \mathrm{~kg} / \mathrm{m}^{2}$ showed favorable postoperative survival compared to those with a normal weight in univariate analysis, but not in multivariate analysis. Considering these findings, we retrospectively assessed the prognostic significance of the Geriatric Nutrition Risk Index (GNRI) [16], a new simplified screening tool to assess the nutrition-related risk that has been shown to be associated with mortality in elderly patients as well as those with various diseases [17-21], in a total of 432 consecutive patients with non -metastatic RCC who received complete surgical resection.

\section{Patients and Methods}

This study retrospectively included 432 consecutive patients who were diagnosed with non-metastatic RCC and subsequently underwent complete surgical resection by either radical or partial nephrectomy between January 2005 and December 2011. Informed consent for this study was obtained from each patient, and the study design was approved by the Research Ethics Committee of our institution.

The 432 patients preoperatively underwent routine blood tests, brain, chest, and abdominal computed tomography, and abdominal magnetic resonance imaging and/or bone scintigraphy. All pathological examinations were performed by a single pathologist according to the 2010 American Joint Committee on Cancer guidelines and the Fuhrman grading system. Information on the clinicopathological characteristics of the included patients was retrieved from their medical records. All patients were generally followed by laboratory as well as radiological examinations at least every 6 months to monitor recurrence and metastasis. In the absence of a relapse of RCC 5 years after surgery, the interval between re-examinations was increased.

GNRI was calculated as follows: GNRI $=1.489 \times$ serum albumin $(g / l)+41.7 \times$ present body weight/ideal body weight [16] The ideal body weight in the present study was defined as the value calculated from the height and BMI of 22 [21], and body weight/ideal body weight was set to 1 , when the patient's body weight exceeded the ideal body weight.

All statistical analyses were performed using Statview 5.0 software (Abacus Concepts, Inc., Berkeley, CA, USA), and p values $<0.05$ were considered significant. The chi-squared test was used to analyze the association between several clinicopathological factors and GNRI. The recurrence-free survival (RFS) and cancer-specific survival (CSS) rates of the patients were calculated by the Kaplan-Meier method, and the differences were determined by the log-rank test. The prognostic significance of certain factors was assessed using the Cox proportional hazards regression model. 

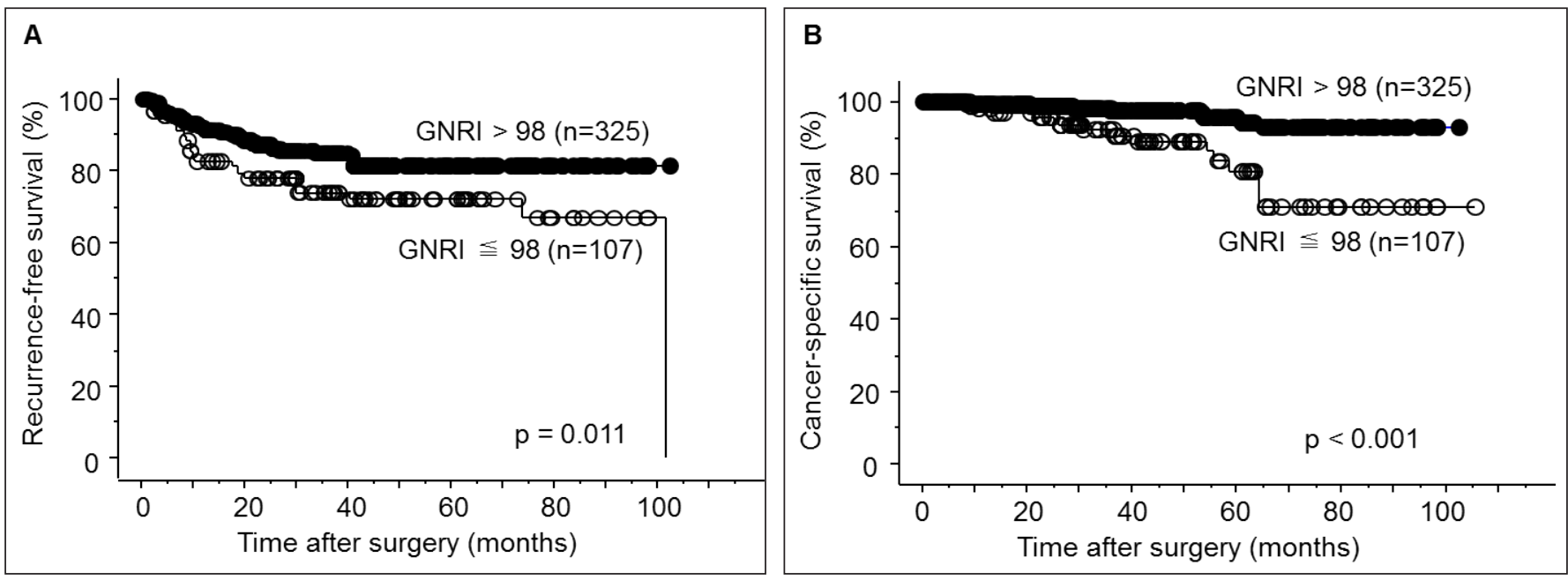

Fig. 1. (A) Recurrence-free survival of patients with non-metastatic renal cell carcinoma who underwent surgical resection according to the Geriatric Nutrition Risk Index. (B) Cancer-specific survival of patients with non-metastatic renal cell carcinoma who underwent surgical resection according to the Geriatric Nutrition Risk Index.

\section{Results}

According to the previously proposed criterion [17], 325 patients $(75.2 \%)$ with GNRI $>98$ were regarded as having a normal nutritional risk, whereas the remaining $107(24.8 \%)$ were judged as having an abnormal nutritional risk. Table 1 presents the characteristics of the patients according to the nutritional risk status. The Karnofsky performance status in the abnormal risk group was significantly lower than that in the normal risk group, while the abnormal risk group had significantly lower levels of hemoglobin, platelets, and albumin as well as higher levels of corrected calcium and C-reactive protein (CRP) than the normal risk group. Furthermore, the proportion of patients with an advanced pathological $\mathrm{T}$ stage or who were positive for microvascular invasion in the abnormal risk group was significantly greater than that in the normal risk group.

During the observation period of this study, disease recurrence occurred in $48(14.8 \%)$ and $28(26.2 \%)$ patients in the normal and abnormal risk groups, respectively, while $9(2.8 \%)$ and $15(14.0 \%)$ patients in the normal and abnormal risk groups, respectively, died of the progression of RCC. The 5-year RFS rates in the normal and abnormal risk groups were 81.6 and $72.2 \%$, respectively, and the 5-year CSS rates in the normal and abnormal risk groups were 94.4 and $81.1 \%$, respectively. As shown in fig. 1, there were significant differences in both RFS and CSS between the normal and abnormal risk groups.
We analyzed the value of GNRI in addition to the conventional prognostic parameters for predicting RFS and CSS in the 432 patients in this study. As presented in table 2, univariate analysis identified gender, hemoglobin, platelets, lactate dehydrogenase, albumin, pathological $\mathrm{T}$ stage, microvascular invasion, the sarcomatoid component, and GNRI as significant predictors of RFS, of which only gender, pathological $\mathrm{T}$ stage, microvascular invasion, and the sarcomatoid component were shown to be independently associated with RFS on multivariate analysis. In addition, univariate analysis indicated that CSS was significantly correlated with albumin, CRP, pathological $\mathrm{T}$ stage, microvascular invasion, the sarcomatoid component, and GNRI. Of these significant factors, only microvascular invasion and GNRI appeared to have independent impacts on CSS on multivariate analysis (table 3).

\section{Discussion}

Altered metabolism plays an important role in the pathogenesis of several types of malignant tumors. In particular, significant progress has been made in the understanding of the metabolic derangements observed in RCC [3-6]. In fact, loss of the VHL gene, which is the most frequently detected genetic disorder in RCC, and the subsequent increase in expression of the hypoxia-inducible factor have been shown to affect several meta- 
Table 2. Uni- and multivariate analyses of several parameters as predictors of recurrence-free survival

\begin{tabular}{|c|c|c|c|c|}
\hline \multirow[t]{2}{*}{ Variables } & \multicolumn{2}{|c|}{ Univariate analysis } & \multicolumn{2}{|c|}{ Multivariate analysis } \\
\hline & Hazard ratio & $\mathrm{p}$ & Hazard ratio & $\mathrm{p}$ \\
\hline Age ( $>70$ years vs. $\leq 70$ years $)$ & 0.83 & 0.443 & - & - \\
\hline Gender (male vs. female) & 2.56 & 0.0012 & 2.79 & $<0.001$ \\
\hline Body mass index $\left(\leq 22 \mathrm{~kg} / \mathrm{m}^{2}\right.$ vs. $\left.>22 \mathrm{~kg} / \mathrm{m}^{2}\right)$ & 1.06 & 0.82 & - & - \\
\hline Neutrophils (> ULN vs. $\leq$ ULN) & 0.91 & 0.84 & - & - \\
\hline Hemoglobin $(<$ LLN vs. $\geq$ LLN) & 1.88 & 0.0061 & 0.96 & 0.87 \\
\hline Corrected calcium $(>10 \mathrm{mg} / \mathrm{dL}$ vs. $\leq 10 \mathrm{mg} / \mathrm{dL})$ & 1.07 & 0.65 & - & - \\
\hline Albumin $(<$ LLN vs. $\geq$ LLN $)$ & 2.52 & $<0.001$ & 2.00 & 0.083 \\
\hline C-reactive protein (> ULN vs. $\leq$ ULN) & 1.14 & 0.22 & - & - \\
\hline Pathological T stage (pT1 vs. pT2 or pT3) & 6.21 & $<0.001$ & 2.89 & $<0.001$ \\
\hline Microvascular invasion (positive vs. negative) & 5.20 & $<0.001$ & 3.26 & $<0.001$ \\
\hline Sarcomatoid component (positive vs. negative) & 4.12 & $<0.001$ & 5.68 & $<0.001$ \\
\hline Geriatric Nutrition Risk Index ( $\leq 98$ vs. > 98) & 1.82 & 0.012 & 0.82 & 0.60 \\
\hline
\end{tabular}

Table 3. Uni- and multivariate analyses of several parameters as predictors of cancer-specific survival

\begin{tabular}{|c|c|c|c|c|}
\hline \multirow[t]{2}{*}{ Variables } & \multicolumn{2}{|c|}{ Univariate analysis } & \multicolumn{2}{|c|}{ Multivariate analysis } \\
\hline & Hazard ratio & $\mathrm{p}$ & Hazard ratio & $\mathrm{p}$ \\
\hline Age $(>70$ years vs. $\leq 70$ years $)$ & 2.04 & 0.082 & - & - \\
\hline Gender (male vs. female) & 1.97 & 0.15 & - & - \\
\hline Body mass index $\left(\leq 22 \mathrm{~kg} / \mathrm{m}^{2}\right.$ vs. $\left.>22 \mathrm{~kg} / \mathrm{m}^{2}\right)$ & 1.99 & 0.10 & - & - \\
\hline Neutrophils (> ULN vs. $\leq$ ULN) & 0.52 & 0.52 & - & - \\
\hline Hemoglobin (<LLN vs. $\geq$ LLN) & 1.88 & 0.13 & - & - \\
\hline Corrected calcium $(>10 \mathrm{mg} / \mathrm{dL}$ vs. $\leq 10 \mathrm{mg} / \mathrm{dL})$ & 2.24 & 0.077 & - & - \\
\hline Albumin $(<$ LLN vs. $\geq$ LLN $)$ & 3.16 & 0.0061 & 0.80 & 0.69 \\
\hline C-reactive protein (> ULN vs. $\leq$ ULN) & 3.99 & $<0.001$ & 1.91 & 0.15 \\
\hline Pathological T stage (pT1 vs. pT2 or pT3) & 6.71 & $<0.001$ & 2.53 & 0.12 \\
\hline Microvascular invasion (positive vs. negative) & 7.71 & $<0.001$ & 3.55 & 0.027 \\
\hline Sarcomatoid component (positive vs. negative) & 9.77 & $<0.001$ & 2.47 & 0.19 \\
\hline Geriatric Nutrition Risk Index ( $\leq 98$ vs. $>98$ ) & 4.49 & $<0.001$ & 3.22 & 0.036 \\
\hline
\end{tabular}

bolic pathways, including glycolysis and oxidative phosphorylation, resulting in enhanced growth and survival of RCC [3]. Moreover, obesity is a widely accepted risk factor for the development of RCC [4, 5]. However, there have been limited studies with respect to the impact of the baseline nutritional status on the prognosis in RCC patients undergoing surgery, and the findings on this issue remain controversial [10-15]. In this study, therefore, we retrospectively analyzed the prognostic significance of the nutritional status evaluated using GNRI in a total of 432 consecutive patients undergoing curative surgery for non-metastatic RCC.
A number of studies have shown the unfavorable impact of a poor nutritional status on both morbidity and mortality in patients with malignant tumors undergoing surgery [7-9]. However, various criteria have been used for the assessment of nutritional deficiency [7-15, 22], and there is still no consensus concerning criteria suitable for predicting the nutrition-related risk in these patients. In fact, when BMI is simply used, conflicting findings on the effect of BMI on the postoperative prognosis of RCC patients have been reported [10-12]. In addition, despite combining several parameters, previously developed criteria, such as the nutritional risk index, nutritional 
risk score, and subjective global assessment, are mainly based on a patient's memory and thus are regarded as subjective tools [22]. Considering these findings, GNRI was used to evaluate the nutrition-related risk, since this criterion is simple and objective, and has been shown to be associated with mortality not only in elderly patients in various health care settings, but also in patients with a wide variety of pathological conditions [16-21].

In this series, $325(75.2 \%)$ and 107 (24.8\%) patients with non-metastatic RCC were judged to have normal and abnormal nutritional risks, respectively, based on the findings of GNRI [17]. According to this classification, patients with an abnormal nutritional risk were shown to be significantly more likely to have several conventional risk factors associated with a poor prognosis, such as an unfavorable performance status, low levels of hemoglobin, platelets and albumin, high levels of corrected calcium and CRP, an advanced pathological $\mathrm{T}$ stage, and microvascular invasion, compared to those with a normal nutritional risk. Several studies have reported findings of the association between the nutritional status and prognostic parameters similar to those in this study [10, 13-15]. For example, Morgan et al. [13] evaluated the nutritional status in RCC patients undergoing surgery using BMI, albumin, and preoperative weight loss, and found a significant impact of nutritional deficiency on age, hemoglobin, pathological T stage, and tumor grade. Although the mechanism by which the nutritional status affects the characteristics of RCC patients associated with postoperative survival has not been fully clarified, one possible explanation is the involvement of tumor-derived inflammatory factors regulated by the nutritional status, such as tumor necrosis factor- [23], which could be supported by the close correlation between GNRI and CRP observed in this study.

We assessed the postoperative prognostic significance of GNRI in patients with non-metastatic RCC, and GNRI was identified as a significant predictor of both RFS and CSS, whereas GNRI appeared to be independently associated with only CSS. To our knowledge, this is the first study showing the significant value of GNRI on the prognosis of patients undergoing cancer surgery. Furthermore, previous studies measuring the nutritional status in RCC patients using objective parameters had findings supporting the present outcomes [13-15]. For example, Ko et al. [14] reported that the nutritional status in RCC patients based on preoperative levels of albumin, cholesterol, and BMI was independently related to progression-free survival and CSS. Collectively, these findings suggest the important role of modification of the nutritional status prior to surgery for patients with non-metastatic RCC, particularly those with biologically aggressive diseases, which may improve their postoperative survival.

There were several limitations of this study. First, although GNRI was assessed in consecutive patients, this was a retrospective study with a comparatively short observation period, and therefore, it was difficult to draw definitive conclusions on the prognostic issues. Second, this study included only Japanese patients and they have been shown to have a nutritional status different from those in Western populations [24]. Therefore, it might be difficult to apply the current outcomes to the overall cohort of RCC patients undergoing surgery. Third, recent advances in the field of molecular-targeted therapy for metastatic RCC could significantly affect CSS, and thus it is necessary to consider this point in the interpretation of the outcomes in this study. Finally, it is essential to conduct prospective studies to confirm the present data and determine the appropriate thresholds of GNRI as a postoperative prognostic indicator for patients with non -metastatic RCC.

In conclusion, nutrition-related risk defined by GNRI could be an important parameter that predicts postoperative cancer-specific mortality in patients with non-metastatic RCC who have undergone curative surgery. 


\section{References}

1 Ferlay J, Shin HR, Bray F, Forman D, Mathers C, Parkin DM: Estimates of worldwide burden of cancer in 2008: GLOBOCAN 2008. Int J Cancer 2010;127:2893-2917.

2 Rini BI, Rathmell WK, Godley P: Renal cell carcinoma. Curr Opin Oncol 2008;20:300306.

3 Sudarshan S, Karam JA, Brugarolas J, Thompson RH, Uzzo R, Rini B, Margulis V, Patard JJ, Escudier B, Linehan WM: Metabolism of kidney cancer: from the lab to clinical practice. Eur Urol 2013;63:244-251.

4 Bergström A, Hsieh CC, Lindblad P, Lu CM, Cook NR, Wolk A: Obesity and renal cell cancer--a quantitative review. $\mathrm{Br} \mathrm{J}$ Cancer 2001;85:984-990.

5 Adams KF, Leitzmann MF, Albanes D, Kipnis V, Moore SC, Schatzkin A, Chow WH: Body size and renal cell cancer incidence in a large US cohort study. Am J Epidemiol 2008; 168:268-277.

6 Gu W, Zhu Y, Wang H, Zhang H, Shi G, Liu $\mathrm{X}, \mathrm{Ye} \mathrm{D}$ : Prognostic value of components of body composition in patients treated with targeted therapy for advanced renal cell carcinoma: a retrospective case series. PLoS One 2015; 10:e 0118022.

7 Schwegler I, von Holzen A, Gutzwiller JP, Schlumpf R, Mühlebach S, Stanga Z: Nutritional risk is a clinical predictor of postoperative mortality and morbidity in surgery for colorectal cancer. Br J Surg 2010;97:92-97.

8 Kanda M, Fujii T, Kodera Y, Nagai S, Takeda S, Nakao A: Nutritional predictors of postoperative outcome in pancreatic cancer. Br J Surg 2011;98:268-274.

9 Gregg JR, Cookson MS, Phillips S, Salem S, Chang SS, Clark PE, Davis R, Stimson CJ Jr, Aghazadeh M, Smith JA Jr, Barocas DA: Effect of preoperative nutritional deficiency on mortality after radical cystectomy for bladder cancer. J Urol 2011;185:90-96.
10 Parker AS, Lohse CM, Cheville JC, Thiel DD, Leibovich BC, Blute ML: Greater body mass index is associated with better pathologic features and improved outcome among patients treated surgically for clear cell renal cell carcinoma. Urology 2006;68:741-746.

11 Kamat AM, Shock RP, Naya Y, Rosser CJ, Slaton JW, Pisters LL: Prognostic value of body mass index in patients undergoing nephrectomy for localized renal tumors. Urology 2004;63:46-50.

12 Schips L, Lipsky K, Zigeuner R, Gidaro S, Salfellner M, Rehak P, Pummer K, Hubmer G: Does overweight impact on the prognosis of patients with renal cell carcinoma? A single center experience of 683 patients. J Surg Oncol 2004;88:57-61.

13 Morgan TM, Tang D, Stratton KL, Barocas DA, Anderson CB, Gregg JR, Chang SS, Cookson MS, Herrell SD, Smith JA Jr, Clark PE: Preoperative nutritional status is an important predictor of survival in patients undergoing surgery for renal cell carcinoma. Eur Urol 2011;59:923-928.

14 Ko K, Park YH, Lee JW, Ku JH, Kwak C, Kim HH: Influence of nutritional deficiency on prognosis of renal cell carcinoma (RCC). BJU Int 2013;112:775-780.

15 Hofbauer SL, Pantuck AJ, de Martino M, Lucca I, Haitel A, Shariat SF, Belldegrun AS, Klatte T: The preoperative prognostic nutritional index is an independent predictor of survival in patients with renal cell carcinoma. Urol Oncol 2015;33:68.e1-7.

16 Bouillanne O, Morineau G, Dupont C, Coulombel I, Vincent JP, Nicolis I, Benazeth S, Cynober L, Aussel C: Geriatric Nutritional Risk Index: a new index for evaluating atrisk elderly medical patients. Am J Clin Nutr 2005;82:777-783.

17 Cereda E, Pusani C, Limonta D, Vanotti A: The ability of the Geriatric Nutritional Risk Index to assess the nutritional status and predict the outcome of home-care resident elderly: a comparison with the Mini Nutritional Assessment. Br J Nutr 2009;102:563-570.
18 Kinugasa Y, Kato M, Sugihara S, Hirai M, Yamada K, Yanagihara K, Yamamoto $\mathrm{K}$ : Geriatric nutritional risk index predicts functional dependency and mortality in patients with heart failure with preserved ejection fraction. Circ J 2013;77:705-711.

19 Jung YS, You G, Shin HS, Rim H: Relationship between Geriatric Nutritional Risk Index and total lymphocyte count and mortality of hemodialysis patients. Hemodial Int 2014; 18:104-112.

20 Yamana I, Takeno S, Shibata R, Shiwaku H, Maki K, Hashimoto T, Shiraishi T, Iwasaki A, Yamashita Y: Is the geriatric nutritional risk index a significant predictor of postoperative complications in patients with esophageal cancer undergoing esophagectomy? Eur Surg Res 2015;55:35-42.

21 Yamada K, Furuya R, Takita T, Yamada K, Furuya R, Takita T: Simplified nutritional screening tools for patients on maintenance hemodialysis. Am J Clin Nutr 2008;87:106113.

22 Poulia KA, Yannakoulia M, Karageorgou D, Gamaletsou M, Panagiotakos DB, Sipsas NV, Zampelas A: Evaluation of the efficacy of six nutritional screening tools to predict malnutrition in the elderly. Clin Nutr 2012;31:378385.

23 Wu Y, Fu X, Zhu X, He X, Zou C, Han Y, Xu M, Huang C, Lu X, Zhao Y: Prognostic role of systemic inflammatory response in renal cell carcinoma: a systematic review and meta-analysis. J Cancer Res Clin Oncol 2011;137:887-896.

24 Sakuta H, Suzuki T: Overweight male personnel of the Japan Self-Defense Forces with body mass indices of 23.0-24.9 and obesity -related metabolic disorders. Environ Health Prev Med 2008;13:116-120. 